\title{
Methodologies of Biophysical Wound Healing Therapies
}

\author{
Jacquelyn Dawn Parente1, Margareta Müller², Knut Möller¹ \\ ${ }^{1}$ Institute of Technical Medicine, Furtwangen University, Villingen-Schwenningen, Germany \\ ${ }^{2}$ Faculty of Mechanical and Medical Engineering, Furtwangen University, Villingen-Schwenningen, Germany \\ Email: pjd@hs-furtwangen.de
}

How to cite this paper: Parente, J.D., Müller, M. and Möller, K. (2016) Methodologies of Biophysical Wound Healing Therapies. J. Biomedical Science and Engineering, 9, 171-179.

http://dx.doi.org/10.4236/jbise.2016.910B022

Received: September 9, 2016 Accepted: September 20, 2016 Published: September 23, 2016

\begin{abstract}
Purpose: To evaluate the effects of methodological variation of biophysical therapies on wound healing outcomes, as a preliminary study to develop a composite wound healing device. Methods: A literature search was focused on the variable devices, system configurations, input parameters, and treatment durations of negative pressure wound therapy (NPWT), electrical stimulation (ES), and low-level light therapy (LLLT) from 2011 to July 2016. Results: In NPWT, lower vacuum pressures of -50 and $-80 \mathrm{mmHg}$ achieved similar tissue perfusion outcomes as earlier recommendations of $-125 \mathrm{mmHg}$, while there is no established regimen with respect to continuous, square wave, or triangular NP waveform due to inconsistent results. Use of wound filler may contribute to improved tissue granulation when compared to topical NP. An ES configuration of high-voltage pulsed current with the stimulation electrode placed in the wound bed best resembles the endogenous skin current, which guides cellular migration. However, no studies have established optimal stimulation parameters. For LLLT, laser and LED proved similarly effective. Although red light has been almost exclusively used in human pressure ulcer treatment, studies comparing blue, green, and red wavelengths more consistently show biological effects using green light. Conclusions: Variation in the application of mechanical, electrical, and radiant energies may be used to modulate wound healing pathways. To 2012, no studies have examined use of these biophysical modalities in combination. Further methodological studies with a systems approach would help define optimal treatment protocols for improved wound healing outcomes in clinical practice.
\end{abstract}

\section{Keywords}

Wound Healing, Therapy, NPWT, HVPC, LLLT, Methodology, Review 


\section{Introduction}

During 2012, approximately 200,000 new patients were added to the growing number of 780,000 Germans living with unhealed wounds for three months or more [1]. Half of these patients received treatment, however as chronic wounds represent a disruption in normal healing pathways, additional treatment beyond standard care wound dressings may be required to complete healing. In response to this clinical need, advanced care technologies are being developed to heal refractory venous leg, diabetic foot, and pressure ulcers.

These treatments may involve application of mechanical, light, or electrical energy to the wounded skin. For example, negative pressure wound therapy (NPWT) applies vacuum pressure to a filled and sealed wound bed, while also removing tissue exudates. Electrical stimulation (ES) applies imperceptible electrical fields across the wound tissue, while low-level light therapy (LLLT) applies blue to near infrared light. Such biophysical-tissue interactions have been shown to re-stimulate the natural healing pathways.

Detailed knowledge of the pathways stimulated by these treatment modalities is growing. NWPT provides fluid removal, yet also derives efficacy from macro- and micro-deformation, the latter being transferred to single cells by the ECM and potentially the integrin-mediated interaction of the cell with the matrix [2]. ES seems to act by enhanced recruitment of mast cells to the wound that may be mediated by so far poorly understood pathways of electrotaxis [3]. Finally, LLLT seems to be acting at least in part through mitochondrial pathways and the generation of reactive oxygen species, the generation of ATP, and the stimulation of transcription factors [4].

Although increasing evidence supports the clinical usage of these therapies, routine treatment protocols have not yet been established. Importantly, variations of equipment and technique may introduce variations at the wound surface that influence healing. Therefore, this review evaluates the effect of variations in methodological approaches of NPWT, ES, and LLLT on healing pathways. Such developments would help define the wound system, establish primary biophysical-tissue interactions, and develop optimized protocols for specific wound healing needs leading towards broader adoption into clinical practice for improved care of chronic wounds.

\section{Literature Search}

This work is a preliminary study towards the design of a composite biophysical wound healing device. Thus, a PubMed database search from 2011 to July 2016 was conducted for reviews in English of NPWT (243 results), ES and wound (200 results), and LLLT and wound (51 results). Notably, selection criterion was for reviews focusing on studies of the effect of variable methodologies on outcomes, rather than efficacy. Therefore, 1 paper was selected for NPWT [5], 0 for ES, and 1 for LLLT [6]. Finally, the search criteria were relaxed to include reviews of the efficacy of ES, while also including a recommendation for selecting stimulation parameters; thus, 2 relevant LLLT review papers were selected. In total, these reviews provided 130 studies of variable methodology 
which were previously reviewed through July 2016. Therefore, this work provides a summary through 2010 (NPWT), 2013 (ES), and 2012 (LLLT) of the effect of methodological variation on wound healing outcomes.

All 43 NPWT studies were in in vitro cell systems or in in vivo animal models; no clinical data were available. Most studies were in porcine models, while tissue perfusion was a commonly reported outcome. Laser and LED were compared in in vitro and in vivo mouse and rat animal models. Additional methodological studies in the LLLT review were selected, which used a range of either wavelength or dosage, and reviewed independently. For ES, 1 paper reviewed randomized controlled trials (RCTs) and observational studies for pressure wounds [7] and the other reviewed 10 RCTs on pressure ulcer, chronic leg ulcers, and diabetic foot ulcers [8].

\section{Results}

\subsection{Mechanical}

Study results are summarized in Table 1 . Amongst the 14 available NPWT systems, no studies have statistically compared device performances or wound interface materials. Transmission of NP is more efficient through perforated drainage conduits inserted into various wound fillers than through a non-perforated drain [9].

As compared to the Redon drain (topical NP), NPWT transmitted through wound fillers results in significantly greater tissue granulation in human sacral pressure ulcers [10]. Both gauze and foam transmitted NP efficiently [11]-[13]; there is no evidence to favor a particular wound filler [5]. However, some preclinical evidence suggests the use of foam may preferentially promote cell proliferation as compared to gauze [14]-[17].

Across a range of NP magnitudes, maximum peak tissue perfusion was initially achieved at $-125 \mathrm{mmHg}$ [23]. Yet, subsequent studies of NP magnitude have achieved similar tissue perfusion, granulation tissue formation, and wound closure outcomes to $-125 \mathrm{mmHg}$ at $-80 \mathrm{mmHg}$ [11] [15] [21] [22] and at -50 [12] [18]-[20]. Studies of NP continuous, square wave, and triangular waveforms have resulted in inconsistent granulation tissue formation outcomes [23] [24]. Thus, new evidence supports the use of a

Table 1. The variable equipment and techniques studied in negative pressure wound therapy (NPWT).

\begin{tabular}{|c|c|c|c|}
\hline Mechanical & \multicolumn{3}{|c|}{ In vitro and in vivo porcine model results [2] } \\
\hline Devices & 14 NPWT systems or Redon drain & Wound filler or topical NP only & NPWT [10] \\
\hline Wound filler & Foam or gauze & Foam and tissue Granulation [14]-[17] & Either [5] \\
\hline Interface material & Impregnated gauze & No statistical studies & Inconclusive \\
\hline NP magnitude & $-25 \mathrm{mmHg}$ to $-400 \mathrm{mmHg}$ & Tissue perfusion modulation & $\begin{array}{l}-50[12][18]-[20] \text { to } \\
-80 \mathrm{mmHg}[11][15][21][22]\end{array}$ \\
\hline NP waveforms & Continuous, square, or triangular wave & Inconsistent results [23] [24] & Inconclusive \\
\hline Treatment duration & Study duration only & - & Inconclusive \\
\hline
\end{tabular}


lower NP magnitude, while there is insufficient evidence to define a NP waveform regimen.

\subsection{Electrical}

Electrode placement in the wound most resembles the skin endogenous electrical field to improve healing rates [25]-[27]. AC stimulation [28] and asymmetric AC pulses [29], resulted in faster healing rates than DC waveforms. Variations in applied voltages [30] and stimulation duration [31] demonstrated a dose-dependent induced cell migration of keratinocytes and fibroblasts [32], respectively. Thus, high-voltage pulsed current (HVPC) stimulation has emerged as a treatment modality with the most clinical potential for use in chronic wound healing, while also minimizing the risk of burns and having a greater depth of current penetration [33] [34].

No studies have compared the methodological parameters of HVPC on wound healing outcomes. Thus, only HVPC parameter ranges can be reported. The commonly used HVPC parameters are summarized in Table 2.

\subsection{Radiant}

Study results are summarized in Table 3. Laser or LED devices differ by their emission mechanisms, however any differences in their light properties are lost during photo-tissue interactions [35] [36]. Accordingly, studies comparing laser and LED for LLLT application have resulted in similar biological effects [6].

All studies comparing the biological effects of blue, green, and red wavelengths for LLLT application showed the effectiveness of green light, while results are inconsistent for blue and red light. In particular, green and red light but not blue light were effective, on increasing fibroblast numbers [37], migratory or proliferative effects [38], or increased angiogenesis [39]. In contrast, green and blue light were effective, but not red

Table 2. The variable equipment and techniques studied in electrical stimulation (ES).

\begin{tabular}{|c|c|c|c|}
\hline \multirow{2}{*}{ Electrical } & \multicolumn{3}{|c|}{ Human pressure ulcer results [4] [5] } \\
\hline & Options & Notes & Selection \\
\hline Waveform & $\begin{array}{l}\text { DC, DC pulse, Symmetric AC pulse, } \\
\text { Asymmetric AC pulse, } \\
\text { High-voltage pulsed current (HVPC) }\end{array}$ & Faster healing rates & HVPC [28]-[33] \\
\hline Stimulation electrode & Anode or cathode & Alternative healing pathways & Inconclusive \\
\hline Stimulation parameters & $\begin{array}{l}50-100 \mu \text { s double-peaked impulses } \\
80-105 \text { pulse per second frequency } \\
50-200 \mathrm{~V} \text { voltage } \\
2-2.5 \text { A peak-current amplitude }\end{array}$ & No optimization studies & Inconclusive \\
\hline
\end{tabular}


Table 3. The variable equipment and techniques studied in low-level light therapy (LLLT).

\begin{tabular}{|c|c|c|c|}
\hline Radiant & \multicolumn{3}{|c|}{ In vitro and in vivo mouse and rat model results [3] } \\
\hline Wavelength & Blue, green, red, near infrared (456 - $1064 \mathrm{~nm})$ & Wavelength-dependent tissue chromophores & Green [37]-[41] \\
\hline Dose & $0.09-90 \mathrm{~J} / \mathrm{cm}^{2}$ & Dose-dependent activation and inhibitory effects & Up to $5 \mathrm{~J} / \mathrm{cm}^{2}[6][42]-[46]$ \\
\hline
\end{tabular}

light, in decreasing wound size [40] or increasing healing rate [41]. Dose values up to 5 $\mathrm{J} / \mathrm{cm}^{2}$ produced the most significant biological effects [6]. In particular, doses of $4 \mathrm{~J} / \mathrm{cm}^{2}$ are more effective than $8 \mathrm{~J} / \mathrm{cm}^{2}$ [42], while doses of 10 and $16 \mathrm{~J} / \mathrm{cm}^{2}$ promoted inhibitory effects [43]-[46]. Finally, variance in output power and exposure time can be modulated to achieve a specified energy density and as a result influence outcomes [47].

\section{Discussion}

The influence of varying negative pressure and strain on tissue perfusion outcomes has been well explored in animal models. Data collected to date suggest the use of wound filler may promote tissue growth. Application of lower NP magnitudes achieved results similar to those at higher NPs; however, a NP waveform regimen has not been optimized. Interestingly, the use of wound filler in NPWT may be associated with promotion of tissue growth. Therefore, more understanding of the physical effect of foam and negative pressure on the internal tissue and vessel pressures, as well as at the cellular level would help in tailoring wound healing needs, in particular, through the modulation of tissue growth and perfusion.

With an appropriately selected electrode configuration and waveform type, application of electrical energy resembles the endogenous skin current. Thus, HPVC has emerged as the leading ES type for healing in human pressure ulcers. However, the lack of methodological studies on the input parameters of HVPC indicates an opportunity for further development. Ongoing debates in this field involve the selection of the anode or cathode electrode for activation, where effects broadly diverge between immune or remodeling healing pathways [48].

In LLLT the use of both laser and LED promote healing and the primary photo-tissue reactions of wavelength-specific light absorption by skin chromophores are well studied. Yet, the exact biological mechanisms resulting in enhanced proliferation are still only partly understood. Interestingly, although red light has almost exclusively been used in human applications, studies using blue, green, and red wavelengths have more consistently resulted in biological effects with green light.

More recent methodological studies, which have not yet been reviewed in the literature, will be more extensively searched and reviewed in the future. While there is an abundance of literature analyzing the effect of each of the above treatment modalities, through 2012, a combination of biophysical modalities for wound healing was not stu- 
died. Specification of such a device should include consideration of the results of these comparative modes, devices, and parameters. Perhaps due to the particular advantages of each biophysical modality-tissue perfusion and edema reduction, immune and cellular stimulation, and reactivation of healing processes-a wisely selected combination of modalities may hold great potential for a significant improvement in the treatment of chronic wounds. Finally, unified reporting of methodological inputs, specifically as biophysical energies, dosages, and treatment durations would greatly contribute to the development of a wound model for control and modulation of wound healing outcomes, as well as a system for studying fundamental biophysical-tissue interactions.

\section{Conclusions}

Mechanical, electrical, and radiant biophysical energies have been used to successfully re-activate wound healing pathways. Variations in their input parameters produce variations in cellular responses, which can be modulated and possibly combined to achieve wound-specific healing outcomes. Further methodological studies with a systems approach would help define treatment protocols and facilitate the adoption of biophysical wound healing treatments into clinical practice for improved wound healing outcomes.

\section{References}

[1] Heyer, K., et al. (2015) Epidemiology of Chronic Wounds in Germany: Analysis of Statutory Health Insurance Data. Wound Repair and Regeneration.

[2] Huang, C., et al. (2014) Effect of Negative Pressure Wound Therapy on Wound Healing. Curr Probl Surg, 51, 301-331. http://dx.doi.org/10.1067/j.cpsurg.2014.04.001

[3] Torkaman, G. (2014) Electrical Stimulation of Wound Healing: A Review of Animal Experimental Evidence. Adv Wound Care (New Rochelle), 3, 202-218.

http://dx.doi.org/10.1089/wound.2012.0409

[4] Chung, H., et al. (2012) The Nuts and Bolts of Low-Level Laser (Light) Therapy. Annals of Biomedical Engineering, 40, 516-533. http://dx.doi.org/10.1007/s10439-011-0454-7

[5] Glass, G.E. and Nanchahal, J. (2012) The Methodology of Negative Pressure Wound Therapy: Separating Fact from Fiction. J Plast Reconstr Aesthet Surg, 65, 989-1001. http://dx.doi.org/10.1016/j.bjps.2011.12.012

[6] Chaves, M.E., et al. (2014) Effects of Low-Power Light Therapy on Wound Healing: LASER x LED. An Bras Dermatol, 89, 616-623. http://dx.doi.org/10.1590/abd1806-4841.20142519

[7] Kawasaki, L., et al. (2014) The Mechanisms and Evidence of Efficacy of Electrical Stimulation for Healing of Pressure Ulcer: A Systematic Review. Wound Repair and Regeneration, 22, 161-173. http://dx.doi.org/10.1111/wrr.12134

[8] Polak, A., et al. (2014) High-Voltage Pulsed Current Electrical Stimulation in Wound Treatment. Advances in Wound Care, 3, 104-117. http://dx.doi.org/10.1089/wound.2013.0445

[9] Malmsjö, M., et al. (2010) Influence on Pressure Transduction When Using Different Drainage Techniques and Wound Fillers (Foam and Gauze) for Negative Pressure Wound Therapy. International Wound Journal, 7, 706-712. http://dx.doi.org/10.1111/j.1742-481X.2010.00706.x

[10] Wild, T., et al. (2008) Definition of Efficiency in Vacuum Therapy-A Randomised Con- 
trolled Trial Comparing with V.A.C. Therapy. Int Wound J, 5, 641-647.

http://dx.doi.org/10.1111/j.1742-481X.2007.00407.x

[11] Borgquist, O., et al. (2010) Micro- and Macromechanical Effects on the Wound Bed of Negative Pressure Wound Therapy Using Gauze and Foam. Annals of Plastic Surgery, 64, 789-793. http://dx.doi.org/10.1097/SAP.0b013e3181ba578a

[12] Malmsjö, M., et al. (2009) Negative-Pressure Wound Therapy Using Gauze or Open-Cell Polyurethane Foam: Similar Early Effects on Pressure Transduction and Tissue Contraction in an Experimental Porcine Wound Model. Wound Repair and Regeneration, 17, 200-205. http://dx.doi.org/10.1111/j.1524-475X.2009.00461.x

[13] Malmsjo, M., et al. (2009) Wound Edge Microvascular Blood Flow: Effects of Negative Pressure Wound Therapy Using Gauze or Polyurethane Foam. Ann Plast Surg, 63, 676-681. http://dx.doi.org/10.1097/SAP.0b013e31819ae01b

[14] Scherer, S.S., et al. (2008) The Mechanism of Action of the Vacuum-Assisted Closure Device. Plastic and Reconstructive Surgery, 122, 786-797.

http://dx.doi.org/10.1097/PRS.0b013e31818237ac

[15] Borgquist, O., et al. (2009) Tissue Ingrowth into Foam but Not into Gauze during Negative Pressure Wound Therapy. Wounds, 21, 302-309.

[16] McNulty, A.K., et al. (2007) Effects of Negative Pressure Wound Therapy on Fibroblast Viability, Chemotactic Signaling, and Proliferation in a Provisional Wound (Fibrin) Matrix. Wound Repair and Regeneration, 15, 838-846. http://dx.doi.org/10.1111/j.1524-475X.2007.00287.x

[17] McNulty, A., et al. (2010) The Consistent Delivery of Negative Pressure to Wounds Using Reticulated, Open Cell Foam and Regulated Pressure Feedback. Wounds, 22, 114-120.

[18] Lindstedt, S., et al. (2008) Impact of Different Topical Negative Pressure Levels on Myocardial Microvascular Blood Flow. Cardiovasc Revasc Med, 9, 29-35. http://dx.doi.org/10.1016/j.carrev.2007.09.001

[19] Lindstedt, S., et al. (2008) A Compare between Myocardial Topical Negative Pressure Levels of $-25 \mathrm{mmHg}$ and $-50 \mathrm{mmHg}$ in a Porcine Model. BMC Cardiovascular Disorders, 8, 14. http://dx.doi.org/10.1186/1471-2261-8-14

[20] Isago, T., et al. (2003) Effects of Different Negative Pressures on Reduction of Wounds in Negative Pressure Dressings. J Dermatol, 30, 596-601. http://dx.doi.org/10.1111/j.1346-8138.2003.tb00441.x

[21] Borgquist, O., et al. (2010) Wound edge microvascular blood flow during negative-pressure wound therapy: examining the effects of pressures from -10 to $-175 \mathrm{mmHg}$. Plast Reconstr Surg, 125, 502-509. http://dx.doi.org/10.1097/PRS.0b013e3181c82e1f

[22] Borgquist, O., et al. (2011) The Influence of Low and High Pressure Levels during Negative-Pressure Wound Therapy on Wound Contraction and Fluid Evacuation. Plast Reconstr Surg, 127, 551-559. http://dx.doi.org/10.1097/PRS.0b013e3181fed52a

[23] Morykwas, M.J., et al. (1997) Vacuum-Assisted Closure: A New Method for Wound Control and Treatment: Animal Studies and Basic Foundation. Ann Plast Surg, 38, 553-562. http://dx.doi.org/10.1097/00000637-199706000-00001

[24] Dastouri, P., et al. (2011) Waveform Modulation of Negative-Pressure Wound Therapy in the Murine Model. Plastic and Reconstructive Surgery, 127, 1460-1466. http://dx.doi.org/10.1097/PRS.0b013e31820a63cb

[25] Karba, R., et al. (1997) DC Electrical Stimulation for Chronic Wound Healing Enhancement Part 1. Clinical Study and Determination of Electrical Field Distribution in the Numerical Wound Model. Bioelectrochemistry and Bioenergetics, 43, 265-270. 
http://dx.doi.org/10.1016/S0302-4598(96)05192-6

[26] Semrov, D., et al. (1997) DC Electrical Stimulation for Chronic Wound Healing Enhancement. Part 2. Parameter Determination by Numerical Modelling. Bioelectrochemistry and Bioenergetics, 43, 271-278. http://dx.doi.org/10.1016/S0302-4598(96)05193-8

[27] Barker, A.T., et al. (1982) The Glabrous Epidermis of Cavies Contains a Powerful Battery. Am J Physiol, 242, R358-R366.

[28] Stefanovska, A., et al. (1993) Treatment of Chronic Wounds by Means of Electric and Electromagnetic Fields. Medical and Biological Engineering and Computing, 31, 213-220. http://dx.doi.org/10.1007/BF02458039

[29] Baker, L.L., et al. (1996) Effect of Electrical Stimulation Waveform on Healing of Ulcers in Human Beings with Spinal Cord Injury. Wound Repair Regen, 4, 21-28. http://dx.doi.org/10.1046/j.1524-475X.1996.40106.x

[30] Nishimura, K.Y., et al. (1996) Human Keratinocytes Migrate to the Negative Pole in Direct Current Electric Fields Comparable to Those Measured in Mammalian Wounds. J Cell Sci, 109, 199-207.

[31] Ahmad, E. (2008) High-Voltage Pulsed Galvanic Stimulation: Effect of Treatment Duration on Healing of Chronic Pressure Ulcers. Ann Burns Fire Disasters, 21, 124-128.

[32] Guo, A., et al. (2010) Effects of Physiological Electric Fields on Migration of Human Dermal Fibroblasts. J Invest Dermatol, 130, 2320-2327. http://dx.doi.org/10.1038/jid.2010.96

[33] Bikson, M., et al. (2009) Establishing Safety Limits for Transcranial Direct Current Stimulation. Clinical Neurophysiology: Official Journal of the International Federation of Clinical Neurophysiology, 120, 1033. http://dx.doi.org/10.1016/j.clinph.2009.03.018

[34] Scheiner, A., et al. (1990) Imbalanced Biphasic Electrical Stimulation: Muscle Tissue Damage. Ann Biomed Eng, 18, 407-425. http://dx.doi.org/10.1007/BF02364157

[35] Enwemeka, C.S. (2006) The Place of Coherence in Light Induced Tissue Repair and Pain Modulation. Photomed Laser Surg, 24, 457. http://dx.doi.org/10.1089/pho.2006.24.457

[36] Karu, T. (1987) Photobiological Fundamentals of Low-Power Laser Therapy. IEEE Journal of Quantum Electronics, 23, 1703-1717. http://dx.doi.org/10.1109/JQE.1987.1073236

[37] de Sousa, A.P., et al. (2010) Effect of LED Phototherapy of Three Distinct Wavelengths on Fibroblasts on Wound Healing: A Histological Study in A Rodent Model. Photomed Laser Surg, 28, 547-552. http://dx.doi.org/10.1089/pho.2009.2605

[38] Fushimi, T., et al. (2012) Green Light Emitting Diodes Accelerate Wound Healing: Characterization of the Effect and Its Molecular Basis in Vitro and in Vivo. Wound Repair Regen, 20, 226-235. http://dx.doi.org/10.1111/j.1524-475X.2012.00771.x

[39] de Sousa, A.P., et al. (2013) Laser and LED Phototherapies on Angiogenesis. Lasers Med Sci, 28, 981-987. http://dx.doi.org/10.1007/s10103-012-1187-Z

[40] Adamskaya, N., et al. (2011) Light Therapy by Blue LED Improves Wound Healing in an Excision Model in Rats. Injury, 42, 917-921. http://dx.doi.org/10.1016/j.injury.2010.03.023

[41] Cheon, M.W., et al. (2013) Low Level Light Therapy by Red-Green-Blue LEDs Improves Healing in an Excision Model of Sprague-Dawley Rats. Personal and Ubiquitous Computing, 17, 1421-1428. http://dx.doi.org/10.1007/s00779-012-0577-3

[42] Medrado, A.R., et al. (2003) Influence of Low Level Laser Therapy on Wound Healing and Its Biological Action upon Myofibroblasts. Lasers Surg Med, 32, 239-244. http://dx.doi.org/10.1002/lsm.10126

[43] Hawkins, D. and Abrahamse, H. (2005) Biological Effects of Helium-Neon Laser Irradiation on normal and Wounded Human Skin Fibroblasts. Photomed Laser Surg, 23, 251-259. 
http://dx.doi.org/10.1089/pho.2005.23.251

[44] Hawkins, D. and Abrahamse, H. (2006) Effect of Multiple Exposures of Low-Level Laser Therapy on the Cellular Responses of Wounded Human Skin Fibroblasts. Photomedicine and Laser Therapy, 24, 705-714. http://dx.doi.org/10.1089/pho.2006.24.705

[45] Houreld, N. and Abrahamse, H. (2007) In Vitro Exposure of Wounded Diabetic Fibroblast cells to a Helium-Neon Laser at 5 and $16 \mathrm{~J} / \mathrm{cm}^{2}$. Photomed Laser Surg, 25, 78-84. http://dx.doi.org/10.1089/pho.2006.990

[46] Houreld, N.N. and Abrahamse, H. (2008) Laser Light Influences Cellular Viability and Proliferation in Diabetic-Wounded Fibroblast Cells in a Dose- and Wavelength-Dependent Manner. Lasers Med Sci, 23, 11-18. http://dx.doi.org/10.1007/s10103-007-0445-y

[47] Lanzafame, R.J., et al. (2007) Reciprocity of Exposure Time and Irradiance on Energy Density during Photoradiation on Wound Healing in a Murine Pressure Ulcer Model. Lasers Surg Med, 39, 534-542. http://dx.doi.org/10.1002/lsm.20519

[48] Sussman, C. and Bates-Jensen, B.M. (2007) Wound Care: A Collaborative Practice Manual. Lippincott Williams \& Wilkins.

Submit or recommend next manuscript to SCIRP and we will provide best service for you:

Accepting pre-submission inquiries through Email, Facebook, LinkedIn, Twitter, etc.

A wide selection of journals (inclusive of 9 subjects, more than 200 journals)

Providing 24-hour high-quality service

User-friendly online submission system

Fair and swift peer-review system

Efficient typesetting and proofreading procedure

Display of the result of downloads and visits, as well as the number of cited articles

Maximum dissemination of your research work

Submit your manuscript at: http://papersubmission.scirp.org/

Or contact jbise@scirp.org 